\title{
Case report on pathogenetic link between gluten and $\lg A$ nephropathy
}

\author{
Stefano Costa ${ }^{1}$, Giovanni Currò ${ }^{1}$, Salvatore Pellegrino ${ }^{1 *}$, Maria Cristina Lucanto ${ }^{1}$, Giovanni Tuccari ${ }^{2}$, Antonio leni ${ }^{2}$,
} Giuseppina Visalli ${ }^{3}$, Giuseppe Magazzù ${ }^{1}$ and Domenico Santoro ${ }^{4}$

\begin{abstract}
Background: A relationship between IgA nephropathy (IgAN) and celiac disease (CD) has been reported. We show the pathogenetic link for the first time.

Case presentation: A 39-year-old man with cystic fibrosis (CF) and CF-related diabetes started to present gross hematuria, back pain and headache. At admission, laboratory analysis showed increase in serum creatinine of 1. $5 \mathrm{mg} / \mathrm{dl}$, together with hematuria and mild proteinuria ( $1 \mathrm{~g} / 24 \mathrm{~h}$ ). He underwent a renal biopsy to investigate the cause of hematuria and renal failure. Biopsy was consistent with IgAN. In view of patient reported dyspepsia, an upper gastrointestinal endoscopy with duodenal biopsies was undertaken and was normal. We looked for mucosal deposits of tTG-2 in the duodenum and the renal mesangium. tTG-2 deposits were found both in the duodenum and in renal biopsies, where they topographically replicated mesangial IgA deposits. After one year on a continued gluten containing diet, the patient developed a Marsh 2 type duodenal pathology.

Conclusions: Our findings suggest a connection between CD and IgAN in terms of an immune-mediated gluteninduced pathogenesis even in the absence of villous atrophy and serum celiac autoantibodies.
\end{abstract}

Keywords: IGA nephropathy, Celiac disease, Tissue transglutaminase, Immunofluorescence technique, Pathogenesis

\section{Background}

A relationship between celiac disease and other autoimmune inflammatory disorders is known [1]. With regardto IgA nephropathy (IgAN), some studies report an increased incidence of celiac disease [2] and postulate a role of gluten in the pathogenesis of this disorder [3, 4]. A double immunofluorescence technique to detect intestinal deposits of anti-tissue transglutaminase IgA was successfully performed in patients with dermatitis herpetiformis (DH) [5] and gluten ataxia (GA) [6] showing a link between gluten and these diseases even in absence of duodenal atrophy or positive celiac serology.

We used this technique to detect anti-TG2 in the mesangium and duodenum of a patient with IgAN.

\section{Case presentation}

A 39-year-old man with CF and CF-related diabetes came to our Unit due to symptoms of pulmonary

\footnotetext{
* Correspondence: salvatorepellegrino2014@gmail.com

${ }^{1}$ Celiac Regional Centre, Pediatric Gastroenterology and Cystic Fibrosis Unit,

University of Messina, Via Consolare Valeria 1, 98125 Messina, Italy

Full list of author information is available at the end of the article
}

exacerbation. At the same time, he started to present gross hematuria, back pain and headache. At admission, laboratory analysis showed increase in serum creatinine of $1.5 \mathrm{mg} / \mathrm{dl}$ together with hematuria and mild proteinuria $(1 \mathrm{~g} / 24 \mathrm{~h})$. Intravenous antibiotics for pulmonary exacerbation (piperacillin/tazobacatam and colimycin) were started and a renal biopsy performed to investigate the cause of hematuria and renal failure. Biopsy was consistent with IgAN (see Fig. 1d), with morphological features of mesangial and endocapillary hypercellularity (Oxford classification M1, E1, S0, T0) [7] As the patient presented dyspepsia, he was offered upper gastrointestinal endoscopy with duodenal biopsies (one from duodenal bulb and three from descending duodenum). Duodenal mucosa was reported as normal on hematoxylin/eosin stain. While compatible HLA alleles for celiac disease (DQ2) were identified, both serum anti-endomysium (EMA) and anti-tissue transglutaminase antibodies (antitTG) were negative. It has been demonstrated that coeliac IgA targets intestinal TG2 early in disease development even when serum celiac autoantibodies are not present. Extraintestinal deposits of coeliac IgA further indicate that 


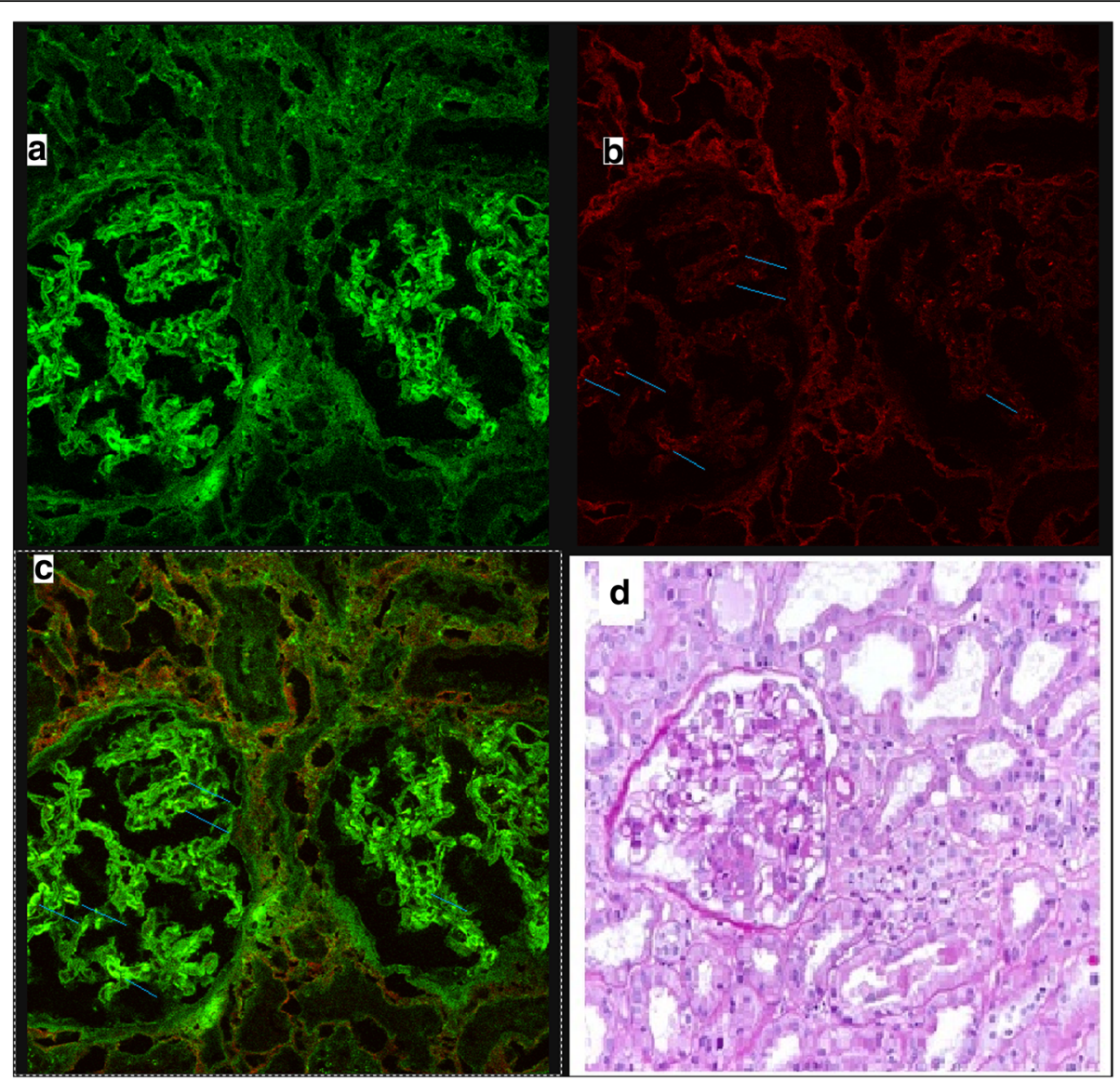

Fig. 1 Renal biopsy. Immunofluorescence (a) showing mesangial deposition of IgA in green. In $\mathbf{b}$, in red, deposition of TG2. In $\mathbf{c}$, the overlap of red and green, in yellow, showing deposition of a-tTG2. The blue lines show the more intense deposition of IgA and TG2. In d, hematoxylin/eosin stain of renal biopsy

humoral immunity may have a pathogenetic role [8]. Therefore, double immunofluorescence on duodenal mucosa was performed to detect mucosal deposits of antitissue transglutaminase type 2 using the technique described by Karponay-Szabo et al., with some modification [8]. Briefly, $5 \mu \mathrm{m}$ sections from the duodenal specimen included in optimal cutting temperature (OCT) compound were obtained and stored at $-80^{\circ}$ in liquid nitrogen. Sections were fixed in acetone and incubated with Normal Rabbit Serum (Calbiochem Germany) for 20 min to block nonspecific sites. Sections were then incubated with antitissue transglutaminase type 2 (anti-tTG-2) from mouse (CUB7402 from Neomarker, Fremont CA) for one hour, and then with secondary antibodies conjugated with fluorochromes to detect total IgA (in green using Polyclonal Rabbit anti-Human IgA/FICT from Dako, Denmark) and anti-tTG-2 (in red using Polyconal Rabbit anti-Mouse RPE F (ab') 2 from Dako, Denmark) for $30 \mathrm{~min}$. The overlap of green and red (yellow) indicates the deposits of anti-tTG2. Analysis was performed on confocal microscopy. The same technique was performed on $5 \mu \mathrm{m}$ renal sections. In both cases, an overlap of green and red in yellow was seen, thus demonstrating deposits of tTG-2 (Fig. 2a, b and c). In particular, in renal biopsies, deposits of tTG-2 that topographically replicated mesangial deposits of IgA (Fig. 1) were detected.

Given the morphological features of IgAN, and the presence of proteinuria, steroid therapy was started according to a standardized six month's protocol [9]. After one month, proteinuria decreased to $100 \mathrm{mg} / 24 \mathrm{~h}$ and hematuria resolved. Steroids were stopped after six months of treatment. The patient continued on a gluten containing diet.

Considering that intestinal deposits of anti-tissue transglutaminase IgA are predictive of forthcoming enteropathy [10] after one year arepeat upper endoscopy was performed even though anti-tTG were still negative. At this time, a Marsh 2 type duodenal pathology was detected (Fig. 3a, b). A gluten free diet was started (for a complete timeline history see Additional file 1: Table S1).

\section{Discussion and conclusions}

To our knowledge, this is the first demonstration of the pathogenetic role of gluten in IgAN. IgAN is a rare complication of CF [11]. In these cases, it is supposed that 


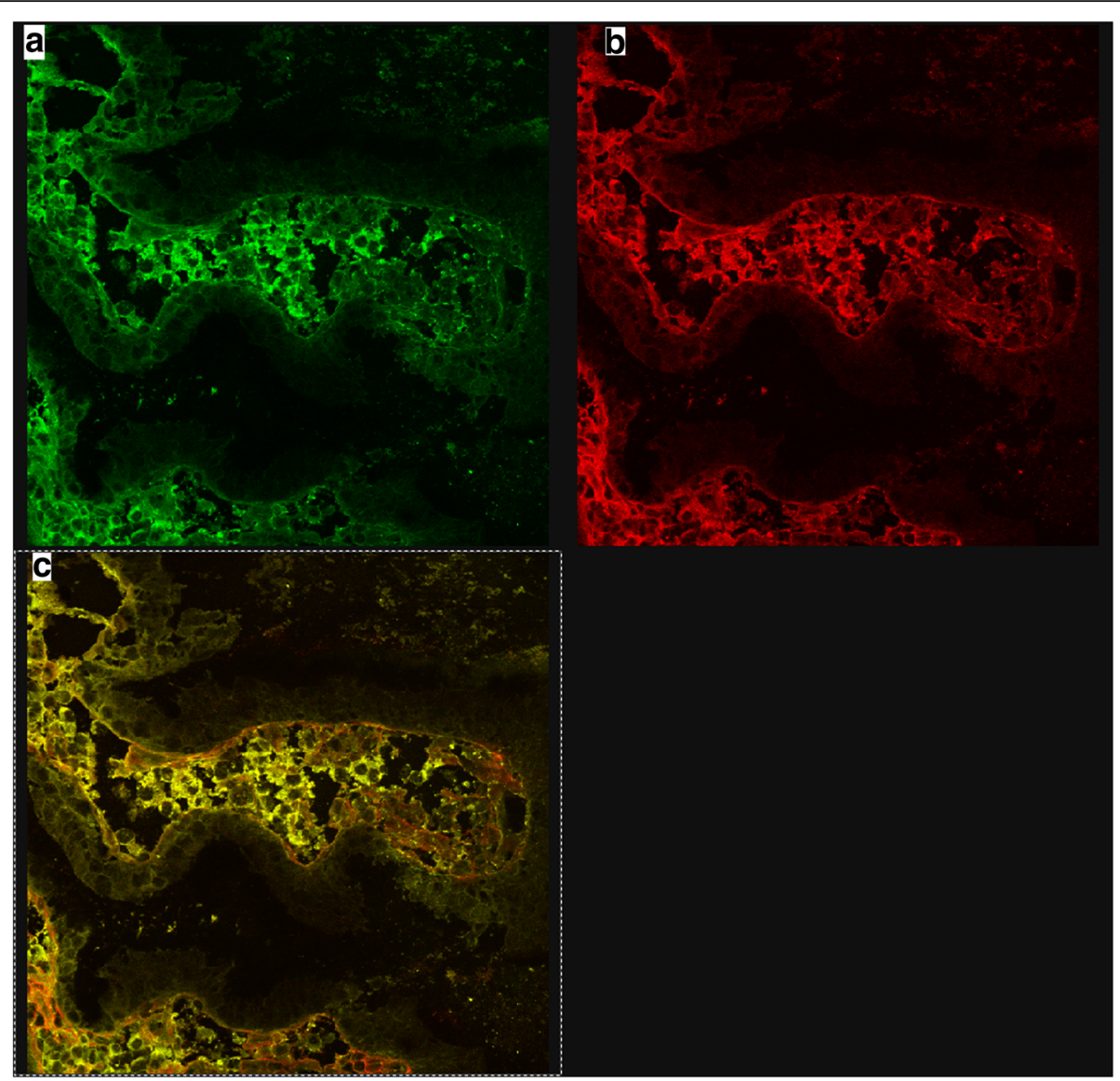

Fig. 2 Duodenal biopsy. In a, deposition of IgA is showed in green. In b, deposition of TG2 is shown in red. In $\mathbf{c}$, in yellow, the overlap of green and red demonstrating the presence of a-tTG2

aninfectious stimulus acts as a trigger. On the other hand, a relationship between CD and IgAN has previously been suggested. In 2002, Collin et al. demonstrated an incidence of $3.6 \%$ of biopsy proven $\mathrm{CD}$ in IgAN [2]. On the other hand, a recent study demonstrated an increased risk of biopsy-verified IgAN among individuals with CD [12]. Another link between these two diseases is represented by the ability of gliadin to act as a lectin and to form immunocomplexes with IgA1N (oligosaccharide-containing IgA). Coppo et al. were able to induce experimental IgAN in mice immunized with gliadin [3]. The same authors showed a positive effect of a gluten free diet on proteinuria and on progression of renal failure in patients with IgAN. Berthelot et al. showed how activation of transglutaminase 2 is crucial for the deposition of immunecomplexes in the mesangium of patients with IgAN [13]. Lechner et al. showed that the removal of IgA deposits by a proteases led to a decrease of TG2 staining thus confirming the presence of the enzyme in mesangial immunocomplexes [14].

In several case reports, an improvement of IgAN is described following a gluten free diet [15-17]. All these cases are characterized by the presence of a biopsy proven $\mathrm{CD}$ and in no caseis a contemporary immune activation in intestine and kidney reported before the development of duodenal atrophy.

Our finding can explain how $\mathrm{CD}$ and IgAN are related. As we found deposits of IgA anti-tissue transglutaminase both in the duodenum and glomerular mesangium we can argue that an autoimmune activation, triggered by gluten in intestinal mucosa and involving tissue transglutaminase, mayoccur in extraintestinal target sites. This kind of association has been demonstrated in other diseases such as GA and in DH, where the role of gluten is well recognized, and a gluten free diet is beneficial [5, 6]. Duodenal atrophy can be absentalso in these diseases, as auto-antibodies production is directed against specific transglutaminase isotypes represented, in dermis, by isotype 3 , and in myelin by isotype 6 , in DH and GA, respectively, In particular, in GA a contemporary presence of anti-tTG2 deposits was found in jejunal mucosa and within the muscular layer of brain vessels and brain parenchyma particularly of the cerebellum, regardless of the presence of duodenal atrophy or positive celiac serology. 


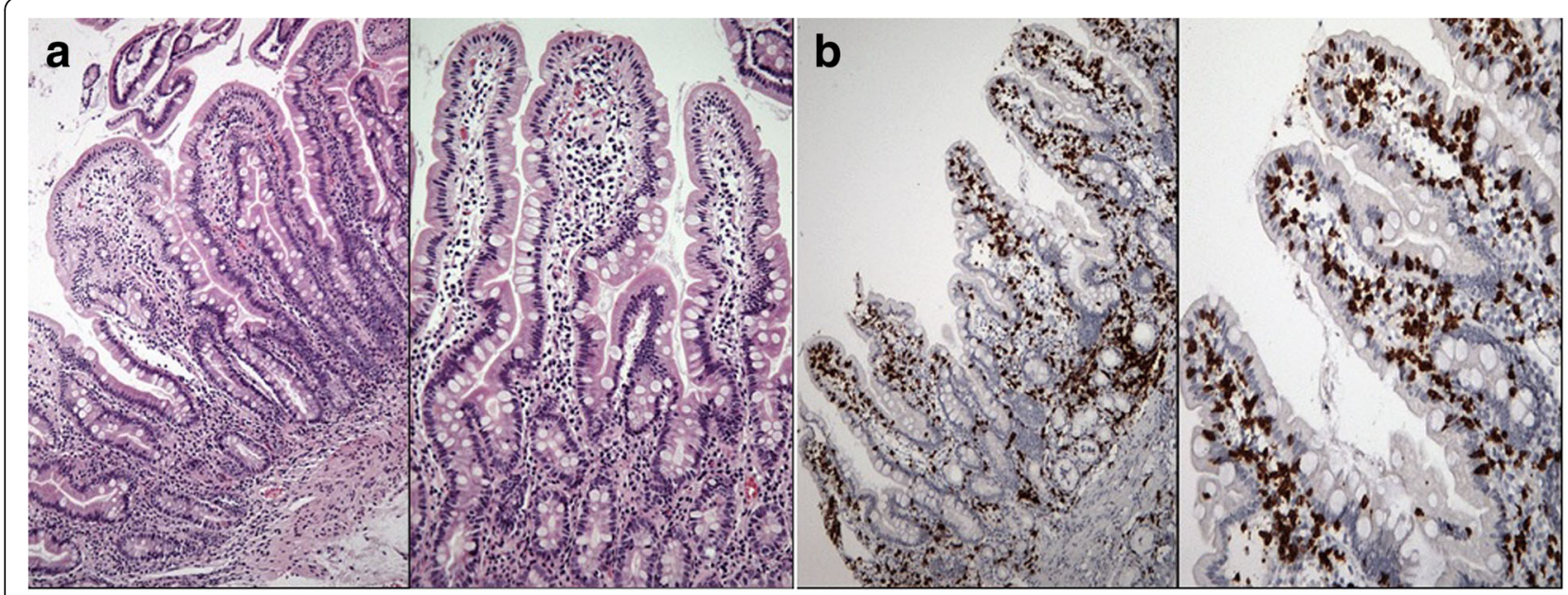

Fig. 3 Duodenal biopsy after one year. In $\mathbf{a}$, hematoxylin/eosin stain showing cryptic hyperplasia. In $\mathbf{b}$, the CD3 immunostained section for the count of intraepithelial lymphocytes

In our case the strength of pathogeneticassociation between CD and IgAN depends on the diagnostic power of the technique we adopted to detect a gluten dependent immune activation. Duodenal deposits oftTG2 are very sensitive and specific for diagnosis of celiac disease, even in the absence of duodenal atrophy and positive celiac serology [18]. Moreover, Salmi et al. [10] showed how mucosal anti-tTG2 deposits strongly predict forthcoming duodenal atrophy.

Actually, after one year, the patient developed a duodenal pathology, thus confirming that intestinal deposits of anti-tTG2 were the initial manifestation of a gluten driven inflammation. As transglutaminase 2 is the most represented isoform in the mesangium, we suggest that mesangial deposition of anti-tTG-2 may play a determinant role in pathogenesis of the disease even in the absence of other signs suggesting celiac disease.

Our findings suggest an immune-mediated gluteninduced pathogenetic link between CD and IgAN even in the absence of villous atrophy and serum celiac autoantibodies. Searching for mesangial deposits of antitTG2 in a large series of new cases of IgAN will allow to define how many cases are caused by this autoimmune mechanism and if a gluten free diet can really improve renal outcome of these patients.

\section{Additional file}

Additional file 1: Table S1. Medical history timeline. (PDF $3430 \mathrm{~kb}$ )

\section{Abbreviations}

CD: Celiac disease; CF: Cystic fibrosis; DH: Dermatitis herpetiformis; EMA: Antiendomysium; GA: Gluten ataxia; IgAN: IgA nephropathy; IgA-tTG: IgA-tissue antitransglutaminase antibodies
Acknowledgements

The authors thank Trays Macdonnell for the English language revision of the article.

Availability of data and materials

Raw data are available upon request to the corresponding author.

\section{Authors' contributions}

SC, GC, SP, DS and GM planned the study, analyzed data and drafted the article. MCL, Al, GT and GV gave substantial contributions to conception and design, acquisition and interpretation of data, revising the article critically for important intellectual content. All authors read and approved the final manuscript.

Ethics approval and consent to participate Not applicable.

\section{Consent for publication}

Written informed consent for publication of clinical details and clinical images was obtained from the patient.

\section{Competing interests}

The authors declare that they have no competing interests.

\section{Publisher's Note}

Springer Nature remains neutral with regard to jurisdictional claims in published maps and institutional affiliations.

\section{Author details}

${ }^{1}$ Celiac Regional Centre, Pediatric Gastroenterology and Cystic Fibrosis Unit, University of Messina, Via Consolare Valeria 1, 98125 Messina, Italy.

${ }^{2}$ Department of Human Pathology of Adult and Evolutive Age 'Gaetano Barresi', University of Messina, Messina, Italy. ${ }^{3}$ Department of Biomedical and Dental Sciences and Morphofunctional Imaging, University of Messina, Messina, Italy. ${ }^{4}$ Department of Clinical and Experimental Medicine, Unit of Nephrology and Dialysis, University of Messina, Messina, Italy.

Received: 14 August 2017 Accepted: 30 April 2018 Published online: 16 May 2018

\section{References}

1. Ventura A, Magazzù G, Greco L. Duration of exposure to gluten and risk for autoimmune disorders in patients with celiac disease. SIGEP Study Group for Autoimmune Disorders in Celiac Disease. Gastroenterology. 1999;117(2):297-303. 
2. Collin P, Syrjänen J, Partanen J, Pasternack A, Kaukinen K, Mustonen J. Celiac disease and HLA DQ in patients with IgA nephropathy. Am J Gastroenterol. 2002;97:2572-6.

3. Coppo R, Amore A, Roccatello D. Dietary antigens and primary immunoglobulin A nephropathy. J Am Soc Nephrol. 1992;2(Suppl 10): S173-80.

4. Papista C, Lechner S, Ben Mkaddem S, LeStang MB, Abbad L, Bex-Coudrat J, Pillebout E, Chemouny JM, Jablonski M, Flamant M, Daugas E, Vrtovsnik F, Yiangou M, Berthelot L, Monteiro RC. Gluten exacerbates IgA nephropathy in humanized micethrough gliadin-CD89 interaction. Kidney Int. 2015;88(2): 276-85

5. Donaldson MR, Zone JJ, Schmidt LA, Taylor TB, Neuhausen SL, Hull CM, Meyer $L$. Epidermal transglutaminase deposits in perilesional and uninvolved skin in patients with dermatitis herpetiformis. J Invest Dermatol. 2007:127:1268-71.

6. Hadjivassiliou M, Mäki M, Sanders DS, Williamson CA, Grünewald RA Woodroofe NM, Korponay-Szabó IR. Autoantibody targeting of brain and intestinal transglutaminase in gluten ataxia. Neurology. 2006;66:373-7.

7. Eitner F, Floege J. Glomerular disease: the Oxford classification-predicting progression of IgAN. Nat Rev Nephrol. 2009;5:557-9.

8. Korponay-Szabo IR, Halttunen T, Szalai Z, Laurila K, Kirly R, Kovács JB, Fésüs L, Mäki M. In vivo targeting of intestinal and extraintestinal transglutaminase 2 by coeliac autoantibodies. Gut. 2004;53:641-8.

9. Pozzi C, Andrulli S, Del Vecchio L, Melis P, Fogazzi GB, Altieri P, Ponticelli C, Locatelli F. Corticosteroid effectiveness in IgA nephropathy: long-term results of a randomized, controlled trial. J Am Soc Nephrol. 2004;15:157-63.

10. Salmi $\Pi$, Collin $P$, Järvinen $\mathrm{O}$, Haimila K, Partanen J, Laurila K, Korponay-Szabo IR, Huhtala H, Reunala T, Mäki M, Kaukinen K. Immunoglobulin Aautoantibodies against transglutaminase 2 in the small intestinal mucosa predict forthcoming coeliac disease. Aliment Pharmacol Ther. 2006;24(3):541-52.

11. Yahiaoui $Y$, Jablonski $M$, Hubert $D$, Mosnier-Pudar $H$, Noël L, Stern $M$, Grenet D, Grünfeld JP, Chauveau D, Fakhouri F. Renal involvement in cystic fibrosis: diseases spectrum and clinical relevance. Clin J Am Soc Nephrol. 2009:4:921-8.

12. Welander A, Sundelin B, Fored M, Ludvigsson JF. Increased risk of IgA nephropathy among individuals with celiac disease. J Clin Gastroenterol. 2013;47:678-83

13. Berthelot L, Papista C, Maciel TT, Biarnes-Pelicot M, Tissandie E, Wang PH, Tamouza H, Jamin A, Bex-Coudrat J, Gestin A, Boumediene A, Arcos-Fajardo M, England P, Pillebout E, Walker F, Daugas E, Vrtosvnik F, Flamant M, Benhamou M, Cogné M, Moura IC, Monteiro RC. Transglutaminase is essential for IgA nephropathydevelopment acting through IgA receptors. J Exp Med. 2012;209(4):793-806.

14. Lechner SM, Abbad L, Boedec E, Papista C, Le Stang MB, Moal C, Maillard J, Jamin A, Bex-Coudrat J, Wang Y, Li A, Martini PG, Monteiro RC, Berthelot L. IgA1 protease treatment reverses mesangial deposits and hematuria in a model of IgA Nephropathy. J Am Soc Nephrol. 2016;27(9):2622-9.

15. Koivuviita N, Tertti R, Heiro M, Metsärinne K. A case report: a patient withlgA nephropathy and coeliac disease. Complete clinical remission followinggluten-free diet. NDT Plus. 2009;2(2):161-3.

16. La Villa G, Pantaleo P, Tarquini R, Cirami L, Perfetto F, Mancuso F, Laffi G. Multiple immune disorders in unrecognized celiac disease: a case report World J Gastroenterol. 2003;9(6):1377-80.

17. Woodrow G, Innes A, Boyd SM, Burden RP. A case of IgA nephropathy with celiac disease responding to a gluten-free diet. Nephrol Dial Transplant. 1993:8(12):1382-3.

18. Kaukinen $\mathrm{K}$, Peräaho $\mathrm{M}$, Collin $\mathrm{P}$, Partanen J, Woolley N, Kaartinen T, Nuutinen T, Halttunen T, Mäki M, Korponay-Szabo I. Small-bowel mucosal transglutaminase2-specific IgA deposits in coeliac disease without villous atrophy: a prospectiveand randomized clinical study. Scand J Gastroenterol. 2005;40(5):564-72.

\section{Ready to submit your research? Choose BMC and benefit from:}

- fast, convenient online submission

- thorough peer review by experienced researchers in your field

- rapid publication on acceptance

- support for research data, including large and complex data types

- gold Open Access which fosters wider collaboration and increased citations

- maximum visibility for your research: over $100 \mathrm{M}$ website views per year

At BMC, research is always in progress.

Learn more biomedcentral.com/submissions 